University of Nebraska - Lincoln

DigitalCommons@University of Nebraska - Lincoln

P. F. (Paul Frazer) Williams Publications

Electrical \& Computer Engineering, Department

March 1982

\title{
Efficient infrared upconversion in Gap
}

M. A. Gundersen

University of Southern California, Los Angeles, California

T. A. Yocom

Texas Tech University, Lubbock, Texas

P. G. Snyder

University of Southern California, Los Angeles, California

P. F. Williams

University of Nebraska - Lincoln, pfw@moi.unl.edu

Follow this and additional works at: https://digitalcommons.unl.edu/elecengwilliams

Part of the Electrical and Computer Engineering Commons

Gundersen, M. A.; Yocom, T. A.; Snyder, P. G.; and Williams, P. F., "Efficient infrared upconversion in Gap" (1982). P. F. (Paul Frazer) Williams Publications. 17.

https://digitalcommons.unl.edu/elecengwilliams/17

This Article is brought to you for free and open access by the Electrical \& Computer Engineering, Department of at DigitalCommons@University of Nebraska - Lincoln. It has been accepted for inclusion in P. F. (Paul Frazer) Williams Publications by an authorized administrator of DigitalCommons@University of Nebraska - Lincoln. 


\title{
Efficient infrared upconversion in GaP
}

\author{
M. A. Gundersen, ${ }^{\text {a) }}$ T. A. Yocom, P. G. Snyder, ${ }^{\text {a) }}$ and P. F. Williams \\ Department of Electrical Engineering, Texas Tech University, Lubbock, Texas 79409
}

(Received 27 July 1981; accepted for publication 3 November 1981)

\begin{abstract}
Mechanisms for linear conversion of infrared to visible were investigated in extrinsic $\mathrm{GaP}$. Efficient (1\%) conversion of 10 micron to visible was observed in GaP:Zn,O. Several device applications are discussed and a quantum counter scheme involving III- $V$ photocathodes is presented.
\end{abstract}

PACS numbers: $85.60 . \mathrm{Gz}, 78.50 . \mathrm{Ge}, 85.60 . \mathrm{Jb}$

\section{INTRODUCTION}

This paper describes a spectroscopic study of extrinsic semiconductor materials for infrared (ir) upconversion applications wherein impurity states provide a mechanism for upconversion of infrared to visible radiation. ${ }^{1-4}$ An upconversion efficiency of $\sim 1 \%$ for $10 \mu \mathrm{m}$ to visible was observed in $\mathrm{GaP}: \mathrm{Zn}, \mathrm{O}$, suggesting that efficient ir detection is possible using impurity doped semiconductors. Previous studies of linear ir upconversion have centered principally on rareearth doped alkali halides. ${ }^{5-7}$ Several ir upconversion schemes employing in-gap semiconductor levels have been considered (Fig. 1) including upconversion to visible through shallow impurity and exciton states ${ }^{2,4,8}$ and deep traps. ${ }^{3}$

Certain impurity-doped semiconductors deserve consideration for ir upconverter applications because they have high radiative quantum efficiency-particularly at low temperature. Radiative quantum efficiencies approaching $100 \%$ have been reported ${ }^{9,10}$ in GaP:Zn,O. In addition, a number of other semiconductor features would be useful for device applications including broad ir and optical bias bandwidth, wide dynamic range, and utilization of material that is technologically well developed.

\section{EXPERIMENTAL}

A visible laser, usually a pulsed nitrogen laser pumped tunable dye laser, was used as the optical bias, and a pulsed infrared laser, either $\mathrm{CO}_{2}(10 \mu \mathrm{m})$ or $\mathrm{H}_{2} \mathrm{O}(23,28,33,48,55$, and $78 \mu \mathrm{m}$ ) was used as the infrared signal. Samples were mounted in a cryostat, and sample temperatures could be varied from $4 \mathrm{~K}$ to room temperature. Fluorescence was observed using either a $1 / 4$ or $1 / 2 \mathrm{M}$ spectrometer and either an optical multichannel analyzer or a photomultiplier.

Upconversion of ir radiation was observed for wavelengths extending to $78 \mu \mathrm{m}$. Results are summarized in Table I. Materials studied (Table I) included $\mathrm{GaP}$ with impurities $\mathrm{N}, \mathrm{S}, \mathrm{Zn}$, and $\mathrm{O}$. Upconversion processes included (1) enhancement of visible fluorescence, (2) fluorescence from a level that does not fluoresce when ir is not incident, (3) fluorescence quenching, and (4) quenching of fluorescence from one impurity level along with enhancement of fluorescence from another impurity level.

Upconversion of $10 \mu \mathrm{m}$ in $\mathrm{GaP}: \mathrm{Zn}, \mathrm{O}$ at $10^{\circ} \mathrm{K}$ was observed through enhancement of a broad emission between

\footnotetext{
"Present address: Department of Electrical Engineering, SSC 420, University of Southern California, Los Angeles, California 90007.
}

710 and $780 \mathrm{~nm}$. The optical bias was $645 \mathrm{~nm}$. Care was taken to verify that enhancement was a photoeffect and not thermal. A calculation of efficiency based on the fluorescence data indicates an internal conversion efficiency of about $1 \%$. Because this result required estimating the amount of light lost in the collection optics, spectrometer, etc., numbers were estimated conservatively, and we believe this is safely on the low side.

\section{DISCUSSION}

Spectroscopic observations in several systems (Table I) and the observed upconversion efficiency in GaP: $\mathrm{Zn}, \mathrm{O}^{9,10}$ suggests several detector applications. For example, as a 10 -

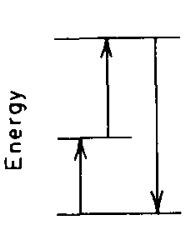

(a)

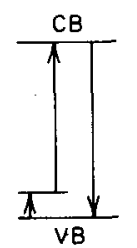

(b)

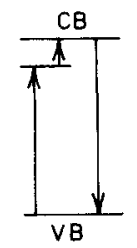

(c)

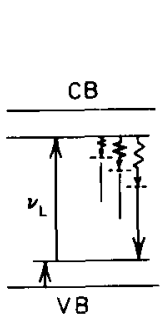

(d)

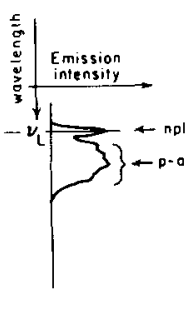

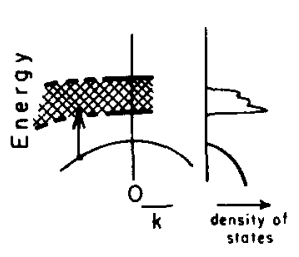

(e)

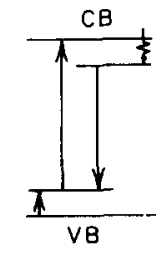

(f)
FIG. 1. Semiconductor ir upconverter diagrams. (a) Upconverter principle. Absorption of 2 photons (optical bias + signal) followed by emission at shorter wavelength. (b),(c) Schematic of processes employing acceptor and donor levels. VB $=$ valence band, $\mathrm{CB}=$ conduction band. Similar processes may be considered for free and bound excitons. In (b) absorption of the optical bias occurs after absorption of ir; in (c) the bias is absorbed first. (d) Intraband process. npl = no-phonon line, $\mathrm{p}$-ar $=$ phonon-assisted recombination, $v_{L}=$ bias photon frequency. Jagged arrow indicates phonon emission. This process would be more characteristic of an indirect gap material. Typically impurity intraband emission is broadened by phonon sideband emission, indicated on right, as well as other mechanisms including donor-acceptor pair distances and density effects. (e) ir absorption broadening mechanisms. $k=$ wave vector. Acceptor level is broadened by density of impurities, and ir photon excites electron from valency band at $k \neq 0$. To the right is plotted hypothetical density of states. (f) Excitation by ir signal to acceptor, followed by excitation to conduction band, followed by nonradiative decay (e.g., trapping) to radiative donor or exciton level. 
TABLE I. Upconversion observations. "

\begin{tabular}{|c|c|c|c|c|c|c|c|c|c|c|c|c|}
\hline & \multirow[b]{2}{*}{ Sample } & \multicolumn{2}{|c|}{$\begin{array}{l}\text { Observed } \\
\text { Pump }\end{array}$} & \multicolumn{2}{|c|}{$\begin{array}{l}\text { Observed } \\
\text { ir signal } \\
\end{array}$} & \multirow{2}{*}{$\begin{array}{l}\text { Quantum } \\
\text { gain } \\
\text { (approx) }\end{array}$} & \multirow{2}{*}{$\begin{array}{l}\text { Est } \\
\text { cutoff } \\
\lambda(\mu \mathrm{m})\end{array}$} & \multirow[b]{2}{*}{ Mechanism } & \multirow{2}{*}{$\begin{array}{l}\text { Observed } \\
\mathrm{As}^{\mathrm{h}}\end{array}$} & \multirow{2}{*}{$\begin{array}{l}\text { Radiative } \\
\text { efficiency }^{c}\end{array}$} & \multirow{2}{*}{$\begin{array}{c}\text { Optimal } \\
\text { pump (est) } \\
(\mu \mathrm{m})\end{array}$} & \multirow[b]{2}{*}{ Comments } \\
\hline & & $\lambda(\mu \mathrm{m}$ & I $\mathrm{eV}$ & $\lambda(\mu \mathrm{m})$ & $\mathrm{eV}$ & & & & & & & \\
\hline (1) & $\mathrm{CdS}^{2}$ & 0.488 & 2.5 & $23-33$ & $\begin{array}{l}0.038 \\
0.054\end{array}$ & 50 & 35 & bound-free exciton & $F$ & $\checkmark$ & 0.488 & $\begin{array}{l}\text { Demonstration of direct } \\
\text { up-conversion using } \\
\text { resonant excitation of } \\
\text { pump level. }\end{array}$ \\
\hline (2) & GaP:Zn,O & 0.65 & 1.9 & 10.6 & 0.124 & 15 & 19 & $\begin{array}{l}e-h \text { pair } \\
\text { recombination }\end{array}$ & $E$ & $V$ & 0.8 & $\begin{array}{l}\text { Measured conversion } \\
\text { efficiency, ir-visible } \geqslant 1 \% \text {. }\end{array}$ \\
\hline (3) & GaP:N $N^{8}$ & $\geqslant 0.535$ & $\leqslant 2.316$ & $10-78$ & $\begin{array}{l}0.016 \\
0.124\end{array}$ & $20-150$ & 120 & $b d$ exciton free & $Q$ & $\checkmark$ & 0.535 & $\begin{array}{l}\text { Exciton bound to } \mathrm{N} \\
\text { with } \simeq 10 \mathrm{meV}\end{array}$ \\
\hline (4) & GaP:S ${ }^{8}$ & $\geqslant 0.535$ & $\leqslant 2.313$ & $10-33$ & $\begin{array}{l}0.028- \\
0.124\end{array}$ & $20-80$ & 50 & $b d$ exciton free & $Q$ & $V$ & 0.536 & $\begin{array}{l}\text { Exciton bound to } S \\
\text { with } \simeq 19 \mathrm{meV} .\end{array}$ \\
\hline (5) & GaP:N, $\mathbf{S}^{8}$ & 0.49 & 2.5 & $10-33$ & $\begin{array}{l}0.028 \\
0.124\end{array}$ & $20-80$ & 65 & $\begin{array}{l}b d \text { exciton-free- } b d \\
\text { exciton }\end{array}$ & $Q, E$ & $V$ & 0.536 & $\begin{array}{l}\text { Employs both bound } \\
\text { excitons in } 4 \text { and } 5 \text {. } \\
\text { Pumping with } \lambda \simeq 5363 \AA \\
\text { should achieve high } \\
\text { conversion efficiency. }\end{array}$ \\
\hline (6) & GaP:Te & $\geqslant 0.535$ & $\leqslant 2.313$ & $10-33$ & $\begin{array}{l}0.028 \\
0.124\end{array}$ & $20-80$ & 50 & $b d$ exciton free & $Q$ & & 0.536 & $\begin{array}{l}\text { Exciton bound to neutral } \\
\text { donor Te with } 19 \mathrm{meV} \text {. }\end{array}$ \\
\hline (7) & Gap:Bi & $\geqslant 0.535$ & $\leqslant 2.3$ & 10 & 0.124 & 20 & 12 & $b d$ exciton free & $Q$ & e & 0.5904 & $\begin{array}{l}\text { Exciton bound to } \\
\text { isoelectronic trap } \mathrm{Bi} \text {. }\end{array}$ \\
\hline
\end{tabular}

Data taken at $T \simeq 10^{\circ} \mathrm{K}$.

${ }^{b} F=$ Fluorescence; $E=$ Fluorescence Enhancement; $Q=$ Fluorescence Quenching.

${ }^{\circ}$ Check indicates radiative quantum efficiency of fluorescing level $10 \%$ to $100 \%$ at $5{ }^{\circ} \mathrm{K}$.

${ }^{d} 0.5360$ will directly excite exciton bound to neutral donor $\mathrm{S}$. This center does not radiate efficiently. ir with $\lambda \leqslant 50 \mu \mathrm{m}$ will photodissociate exciton, which may then bind to N. Quantum efficiency for N-bound exciton is very high, approaching $100 \%$ in samples easily available, and emission is broadened and easily detectable.

${ }^{e}$ Estimated for direct pump excitation to be $>50 \%$ based on studies of isoelectronic traps in GaP.

$\mu \mathrm{m}$ detector Gap:Zn,O should be fast ( $>100 \mathrm{MHz}$ ) with good quantum efficiency, and high-quality material can be straightforwardly prepared. In addition, it is often required that the bias and/or signal have narrow frequency spreadeither to precisely match absorption features in the material (for linear devices) or to achieve phase matching (in a nonlinear device). This tends to restrict applications somewhat. Typically both the signal and bias absorption features are broad in the extrinsic semiconductor materials. Thus in $\mathrm{GaP}: \mathrm{Zn}, \mathrm{O}$ and similar materials there should be a broad band ir response-extending from beyond $19 \mu \mathrm{m}$ to the near ir.

It may be possible to take advantage of this method to use the negative electron affinity photocathode for the detection of middle and far infrared radiation. In commercial negative electron affinity devices, $p$-type $\mathrm{GaP}, \mathrm{GaAsP}$, and InGaAsP are used. ${ }^{11-13}$ Heavy $p$-type doping is used-typically $\mathrm{Zn}\left(10^{18}-10^{19} / \mathrm{cm}^{3}\right)$-to achieve a very small band-bending region at the emitting surface. The work function of the semiconductor surface is lowered by the application of cesium and oxygen. The combination of work function lowering and band bending yields a high escape probability for photogenerated electrons from these III-IV materials. ${ }^{13}$ It may be possible to incorporate the acceptor level in a negative electron affinity device as the intermediate state in a quantum upconverter, thus using the ir to be detected to excite an electron to the acceptor site from the valence band, and then exciting the electron to the conduction band with an optical bias-such as emission from a light emitting diode resonant with the energy difference between the acceptor state and the conduction band. Such a device could have a large surface and broad bandwidth (up to $\sim 1 \mathrm{gHz}$ ).

Several problems deserve mention and further study for the development of a device. The intermediate state lifetime determines the requirement on optical bias intensity. Such lifetimes vary considerably; in GaP from $\sim 10$ ns to $>1 \mathrm{~s}$, depending on the impurities. In order for the process to be efficient the ir absorption cross section must be large, and the pump intensity must be sufficient to provide the second excitation step before recombination occurs, e.g.,

$$
n \gtrsim 1 / \sigma T \text {. }
$$

where $n=$ number of bias photons per $\mathrm{cm}^{2} \mathrm{~s}, \sigma=$ bias absorption cross section and $T=$ intermediate state lifetime. In practice a source of noise may be the absorption of bias photons by valence band electrons; whether or not this occurs will in general depend on the semiconductor-impurity system. For a sensitive device, a low background of fluorescence is necessary. Thus if excitation by the optical bias occurs to the intermediate state from the valence band, the system would be unsuitable for a device with good detectivity-although the quantum efficiency may be high. In addition, the separation of the acceptor level from the valence band must be considered. If the doping level is as high as in 
negative electron affinity devices, the valence band will be essentially degenerate with the acceptor level, and the effective acceptor density of states may be even higher than the valence band density of states. It would be necessary to reduce the acceptor doping to avoid degeneracy with the valence band, hence reducing the bending effect. Finally, for an efficient negative electron affinity type device it is also necessary that the ir absorption length be comparable to the carrier diffusion length.

The mechanism for upconversion in GaP:Zn, O is probably that indicated in Fig. 1(d), with the intraband states being those associated with the exciton bound to $\mathrm{Zn}-\mathrm{O} .{ }^{10}$ This mechanism suggests the possibility of an internal conversion efficiency greater than one-more than one visible photon produced for each absorbed ir photon. This is because the radiative recombination is intraband, and the lower state may be re-excited by another bias photon. Furthermore, there should be little absorption of the emitted radiation because most of the emission is through phononassisted sidebands [Fig. 1(d)]. Thus it may be possible to obtain gain in a classical sense in an optical system.

\section{ACKNOWLEDGMENTS}

It is a pleasure to acknowledge valuable discussions with J. S. Escher and W. L. Faust. This work was supported by a grant from the Engineering Division of the National Science Foundation.

'The principle is described in N. Bloembergen, Phys. Rev. Lett. 2, 84 (1959).

${ }^{2}$ M. A. Gundersen, Appl. Phys. Lett. 24, 591 (1974).

${ }^{3}$ B. Clerjaud, F. Gendron, and C. Porte, Appl. Phys. Lett. 38, 212 (1981).

${ }^{4}$ M. A. Gundersen, T. A. Yocom, P. G. Snyder, and P. F. Williams, SPIE J. 236, 283 (1980).

${ }^{5}$ L. Esterowitz, A. Schnitzler, J. Noonan, and J. Bahler, Appl. Opt. 7, 2053 (1968).

${ }^{6}$ L. F. Johnson, H. J. Guggheim, T. C. Rich, and F. W. Ostermayer, J. Appl. Phys. 43, 1125 (1972).

'W. E. Case, J. S. Chivjan, and P. W. Reynolds, J. Appl. Phys. 50, 4509 (1979).

${ }^{8}$ M. A. Gundersen and W. L. Faust, Phys. Rev. B 7, 3681 (1973).

${ }^{9}$ M. Gershenzon and R. M. Mikulyak, Appl. Phys. Lett. 8, 245 (1966).

${ }^{10} \mathrm{~B}$. Welber and T. N. Morgan, Phys. Rev. 170, $767(1968) ; \mathrm{Zn}$ and $\mathrm{O}$ related recombination are discussed in J. D. Cuthbert, C. H. Henry and P. J. Dean, Phys. Rev. 170, 739 (1968); J. M. Dishman, M. D. Domenico Jr., and R. Caruso, Phys. Rev. B 2, 1988 (1970); G. F. Neumark et al., Phys. Rev. B 15, 3147 (1977).

''J. S. Escher, G. A. Antypas, and J. Edgecume, Appl. Phys. Lett. 29, 153 (1976); J. S. Escher and G. A. Antypas, Appl. Phys. Lett. 30, 314 (1977). ${ }^{12}$ W. E. Spicer, Appl. Phys. 12, 115 (1977).

${ }^{13}$ J. S. Escher (private communication) 